\title{
Pathogenesis of HIV in the Central Nervous System
}

\author{
Victor Valcour • Pasiri Sithinamsuwan • \\ Scott Letendre $\cdot$ Beau Ances
}

Published online: 31 December 2010

(C) The Author(s) 2010. This article is published with open access at Springerlink.com

\begin{abstract}
HIV can infect the brain and impair central nervous system (CNS) function. Combination antiretroviral therapy (cART) has not eradicated CNS complications. HIVassociated neurocognitive disorders (HAND) remain common despite cART, although attenuated in severity. This may result from a combination of factors including inadequate treatment of HIV reservoirs such as circulating monocytes and glia, decreased effectiveness of cART in CNS, concurrent illnesses, stimulant use, and factors associated with prescribed drugs, including antiretrovirals. This review highlights recent investigations of HIV-related CNS injury with emphasis on cARTera neuropathological mechanisms in the context of both US and international settings.
\end{abstract}

\footnotetext{
V. Valcour $(\bowtie)$

Memory and Aging Center,

University of California - San Francisco,

Suite 905, 350 Parnassus Avenue,

San Francisco, CA 94143-1207, USA

e-mail: Vvalcour@memory.ucsf.edu

P. Sithinamsuwan

Division of Neurology, Department of Medicine,

Phramongkutkloa Hospital,

315 Ratchvidhi Road, Thung Phyathai, Ratchthewi,

Bangkok 10400, Thailand

e-mail: pasiripmk@gmail.com

S. Letendre

HIV Neurobehavioral Research Center,

University of California - San Diego,

220 Dickinson Street, Suite A,

San Diego, CA 92103, USA

e-mail: sletendre@ucsd.edu

\section{B. Ances}

Department of Neurology, Washington University,

Box 8111, 660 South Euclid Avenue,

Saint Louis, MO 63110, USA

e-mail: bances@wustl.edu
}

Keywords AIDS dementia complex · Aging · Review · Cerebrospinal fluid

\section{Introduction}

HIV is neurovirulent, with clinically relevant central nervous system (CNS) symptoms observed in more than $50 \%$ of patients not receiving combination antiretroviral therapy (cART) [1•]. The introduction of antiretroviral therapies more than a decade ago resulted in profound declines in morbidity and mortality and raised hopes for the eradication of CNS complications. While the prevalence of opportunistic infections decreased markedly, HIVassociated neurocognitive disorders (HAND) remain frequent, although often not diagnosed and typically with milder symptoms $[1 \bullet]$. These more subtle forms of HAND can greatly impact daily functioning and predict non-CNS morbidity and mortality [2].

Blood tests such as CD4+ lymphocyte counts and plasma HIV RNA levels are typically used in clinical settings to estimate the severity of HIV disease and cART effectiveness. Except in the face of dementia, the impact of HIV on cognition and the assessment of cART effectiveness in the CNS have not typically entered into decisions of when to start therapies or which drugs to start in clinical settings. Recently, several aspects of this paradigm have been challenged, including consideration for CNS-specific effectiveness into therapeutic decision making, the role of inadequately treated peripheral reservoirs, and the potential need for more complete suppression of inflammatory pathways. Antiretroviral side effects including metabolic derangements may impact brain function. The convergence of aging and HIV have CNS implications, raising the possibility of accelerated neurodegenerative syndromes. 
The release of newer antiretrovirals with safer side effect profiles and effectiveness against resistant virus means that most patients who are adherent can suppress HIV RNA in plasma. To best inform future treatment options, research should more purely focus on neuropathological mechanisms of CNS injury in the setting of suppressed HIV RNA in plasma. This review emphasizes such studies.

\section{Epidemiology and Clinical Manifestations of CNS Injury in the Era of cART}

The proportion of individuals with cognitive impairment by disease stage has not changed over the past two decades, despite single, double, or triple combination ART introduced over this period. Current estimates find that nearly $50 \%$ of HIV patients in the United States demonstrate neuropsychological testing performance that is below expectations compared to age, education, gender, and ethnicity matched normative groups [1•]. Among these cases, about half are symptomatic and few meet research classification of dementia. Cognitive impairment has been identified in all international settings where it has been investigated; yet the prevalence of HAND varies considerably by region. Much of the variability can be explained by disease stage, treatment, and the instruments used to detect impairment. Region-specific characteristics seem to be important also, including the types of coexisting morbidities and the HIV subtypes that are prevalent [3].

In 2007, a consensus panel redefined research diagnostic categories of HAND, identifying HIV-associated dementia (HAD) as the most severe form of injury (Table 1). Mild neurocognitive disorder (MND) represents a milder form of impairment that still impacts daily activities of living [4]. A category termed asymptomatic neurocognitive impairment (ANI) was introduced to recognize individuals with impairment on neuropsychological testing who report functional limitations. Compared to other dementias, such as Alzheimer's disease (AD) where collateral sources are available, HIV + subjects often present without proxy informants, likely influencing the accuracy of functional assessments particularly when insight is impaired. Thus, it is possible that with more accurate estimates of impairment, ANI cases would qualify as having symptomatic disease. There are few data to inform the longitudinal outcomes associated with ANI diagnosis.

While it is tempting to consider that MND is a milder and earlier stage of HAD, there are no data to suggest that an HIV patient with MND will universally progress to HAD. Instead, a fluctuating course may occur with some patients having improvement with time $[4,5]$. Indeed, the very low prevalence of HAD in the era of cART supports that HAD is not an inevitable consequence of MND in a manner seen in typical neurodegenerative syndromes such as $\mathrm{AD}$. It remains unclear whether the pathologies of MND and HAD overlap or are distinct. The impact of HIV on brain function differs somewhat from noninfectious neurodegenerative disorders where early disease is often heralded by focal CNS involvement [6]. In contrast, HIV has a broader CNS impact with emphasis on deep grey matter structures and subcortical regions in a manner that underscores the clinical syndrome that involves cognitive, motor, and behavioral manifestations. Apathy and depression are frequent findings in HIV and correlate to disease markers and CNS anatomic changes [7, 8]. Motor impairment remains an identifiable aspect of HAND with increasing frequency among aged individuals [9].

There are limitations to the currently defined cognitive schemas. They rely heavily on comprehensive neuropsychological testing; however, the ability to administer these tests, which can last more than three hours, is impractical for the busy clinical setting, particularly in low-income countries. Although brief dedicated instruments such as the HIV Dementia Scale have been developed, their sensitivity varies in different reports and by educational status [10]. The 2007 criteria have been primarily applied in research rather than clinical settings and the long-term clinical outcomes related to these definitions remain unclear. These
Table 1 Research criteria for HIV-associated neurocognitive disorders [4]

\begin{tabular}{|c|c|c|}
\hline Diagnostic entity & Cognitive performance & Functional performance \\
\hline Normal cognition & Normal & Normal \\
\hline $\begin{array}{l}\text { Asymptomatic } \\
\text { neurocognitive } \\
\text { impairment }\end{array}$ & $\begin{array}{l}\text { Acquired impairment in at } \\
\text { least } 2 \text { cognitive domains }(<1 \mathrm{SD})\end{array}$ & Does not impact daily function \\
\hline $\begin{array}{l}\text { Mild } \\
\text { neurocognitive } \\
\text { disorder }\end{array}$ & $\begin{array}{l}\text { Acquired impairment in at least two } \\
\text { cognitive domains }(<1 \mathrm{SD})\end{array}$ & $\begin{array}{l}\text { Interferes with daily function to at } \\
\text { least a mild degree (eg, work } \\
\text { inefficiency, reduced mental acuity) }\end{array}$ \\
\hline $\begin{array}{l}\text { HIV-associated } \\
\text { dementia }\end{array}$ & $\begin{array}{l}\text { Acquired impairment in at least } 2 \text { domains, } \\
\text { typically in multiple domains with at least } \\
2 \text { domains with severe impairment } \\
(<2 \text { SD) }\end{array}$ & Marked impact on daily function \\
\hline
\end{tabular}


limitations restrict the capacity to make firm recommendations related to the approach and timing of screening and highlight the need for longitudinal validation data.

\section{Neuropathology in the Era of cART}

HIV quickly enters the brain after initial exposure, probably through infected monocytes and lymphocytes that cross the blood brain barrier (BBB). Although neurons are not infected by HIV, they can be injured via indirect mechanisms, including viral proteins, such as gp120 and tat, and neurotoxins resulting from the neurological immune response. HIV encephalopathy is characterized by gliosis, microglial nodules, perivascular macrophage accumulation, and the presence of multinucleated giant cells. Immune activation (encephalitis) is often out of proportion to the amount of HIV virus present in the brain. One model of HIV encephalitis, macaques that have been infected with simian immunodeficiency virus (SIV) and had their CD8+ $T$ cells depleted, identified a pattern of monocytes trafficking from bone marrow as a correlate to encephalitis with newly arriving brain macrophages demonstrating recent transmigration [11•]. The demonstration that these cells transition from bone marrow is consistent with an informative case of HAD in humans where the viral signature in deep brain structures was most consistent with that in bone marrow and circulating monocytes and a finding that peripheral monocytes HIV DNA levels correlate to HAND in the current era $[12,13]$. Together, these data raise concern that peripheral reservoirs continue to play an active role in brain injury despite cART.

Reports of the neuropathology of HIV in the era of cART have been mixed. One study demonstrated a less aggressive degree of immune activation compared to that seen in the pre-cART era; however, more than $70 \%$ of autopsy cases had some abnormality [14]. In a separate study, despite plasma HIV RNA suppression, high levels of microglial/macrophage activation in the basal ganglia and hippocampus were seen [15]. In a third series using highly sensitive assays, HIV RNA was identified in about half of subjects at autopsy, despite most subjects having access to cART [16]. The highest concentrations were noted in caudate nucleus whereas lowest concentrations were noted in cerebrospinal fluid (CSF), suggesting that HIV RNA levels in CSF may underestimate HIV replication in brain tissue. Astrocyte infection occurs, particularly in HAD with infected astrocytes more typically adjacent to perivascular macrophages and often harboring latent, nonproductive virus [17]. Based on in vitro macrophage/astrocytes coculture experiments, astrocytes likely play a key role in immune activation and chemotaxis [18]. Potentially reversible synaptic-dendritic neuronal damage has been described
[19••]. The potential reversibility would be consistent with clinical findings of fluctuating symptoms and this alternative mechanism of CNS injury would be parsimonious with the less aggressive levels of inflammation noted in the cART era.

\section{Aging and Neurodegenerative Disorders}

Age is consistently identified as a risk factor for cognitive impairment in HIV. As HIV patients age due to successful treatment paradigms, there is growing concern of accelerated risk for neurodegenerative disorders. In HIV-negative groups, neurodegenerative disorders are characterized by abnormal brain tissue protein accumulation including ubiquitin, amyloid-beta, tau and alpha synuclein. There is a growing body of knowledge supporting abnormal brain protein accumulation in HIV. Recent reports note excess hyper-phosphorylated tau, amyloid, and alphasynuclein, particularly in older HIV subjects [20-22]. In patients without HIV encephalitis, age-associated intracellular amyloid- $\beta$ staining of pyramidal neurons along axonal tracts has been described [22]. Levels of CSF amyloid- $\beta_{1-42}$ noted in patients with HAND are similar to that seen in $\mathrm{AD}$ [23].

Whether these changes predispose to neurodegeneration is unknown. Indeed, novel neurological imaging with the tracer Pittsburgh compound $\mathrm{B}$ (PIB), which binds to amyloid- $\beta_{1-42}$ with specificity for $\mathrm{AD}$-type neuritic plaques rather than soluble amyloid, oligomers, or diffuse plaques, did not identify increased amyloid in cognitively normal HIV subjects [24]. However, this study was completed in subjects who were younger, conferring a lower overall risk for AD. Data from other CSF studies further suggest that the neuropathogenic pathways to CNS injury in HIV have distinct features compared to those of $\mathrm{AD}$ [25].

\section{The Effectiveness of cART in the CNS}

The BBB can exclude from the CNS many large molecules, including numerous medications. Data comparing HIV RNA responses in CSF and plasma along with knowledge of individual antiretroviral characteristics support the concept that antiretrovirals differ in their ability to permeate the BBB in therapeutic concentrations and have led to the development of CNS penetration-effectiveness (CPE) estimates [26]. CSF measurements are only a surrogate for concentrations in the brain and may be over or under estimates. A postmortem report noted HIV in brain tissue more frequently than in CSF [16] and one report from an animal model of SIV encephalitis, a condition most similar to HIV meningitis, demonstrates CNS improvement despite 
estimated poor BBB penetration of antiretroviral regimens [27]. An important note is that cART effectiveness, as estimated by suppression of HIV RNA in plasma, is likely the strongest determinant of HIV RNA response in CSF.

There have been reports that the CNS can harbor virus that is discordant from virus in plasma, supporting the concept that the CNS environment, including drug pressure, is distinct from blood and lymphoid tissue. A recent case series identified 11 patients with new-onset neurologic symptoms who were found to have CSF levels of HIV RNA out of proportion to that in plasma [28]. The investigators modified the cART regimens based on drug resistance patterns in CSF and on CPE estimates, with the result that all responded with clinical improvement and reductions in HIV RNA in CSF. Recent abstracts identified that CSF HIV RNA may occur despite suppression in plasma at a rate of between $3 \%$ and $10 \%$ among treated individuals [29]. A separate case report of HAD demonstrated viral evolution in CNS that differed from that in plasma [30].

While most studies demonstrate that cART with better CPE is associated with viral suppression in CSF, early reports on the clinical impact have been mixed. For example, in a prospective cART initiation observational study, higher CPE ranks were associated with greater improvements in neuropsychological performance among individuals with HAND [31]. In contrast, a similar prospective study failed to identify a clinical cognitive benefit to initiating regimens with higher CPE ranks [32]. Among perinatally HIV-infected children, higher CNSpenetrating regimens were associated with a survival benefit [33]. Furthermore, there are early data to suggest that CSF suppression to below 2 copies $/ \mathrm{mL}$ may have a cognitive benefit, which may highlight an important clinical need for more sensitive HIV RNA assay [34].

The observational data to date provide support for considering drug penetration and neurological effectiveness data when selecting new cART for people with HAND [35] but must be applied with more caution when adjusting stable therapy in people with HAND who have already achieved viral suppression in plasma with their current cART. Importantly, these data cannot be applied with confidence to selection of cART for neurologically asymptomatic individuals for the objective of preventing HAND. Future research efforts should broadly include systemic morbidities and adherence since altering treatment regimens may affect non-CNS outcomes. There is a need for larger sample sizes and a more uniform scientific approach in these studies in a manner that supports cross-cohort comparisons. Several new clinical trials are opening to address these objectives.

The focus on optimization of cART to reach therapeutic concentrations in CNS addresses control of HIV replication in resident cells but does not address the important mechanism of continued transmigration during therapy. Hematopoietic bone marrow cells likely harbor HIV infection before releasing cells into circulation [36], and recent findings from animal models demonstrate movement of SIV-infected, bone marrow-derived monocytes to the CNS perivascular space [11•]. Among cART-treated subjects with suppressed plasma HIV RNA, low-level HIV DNA infection of peripheral mononuclear cells correlates to HAND [37] and levels of HIV DNA in circulating monocytes remain elevated among impaired subjects 1 year after cART with suppression of plasma HIV RNA [38]. It is increasingly evident that events occurring in the earliest days of infection have a profound immunological impact, possibly altered by early treatment. Antiretroviral treatment initiation during primary compared to chronic infection also impacts peripheral HIV DNA reservoirs, providing some support for potential treatment options (Fig. 1) [39].

\section{Neurological Imaging in the Era of cART}

Neuroimaging provides an important contribution in HIV by distinguishing lesions due to opportunistic infections. To provide benefit in HAND, an ideal neuroimaging biomarker should 1) diagnose HIV-related CNS injury; 2) detect presymptomatic changes due to HIV; and 3) assess treatment effects. In the pre-cART era, numerous studies demonstrated atrophy particularly within subcortical structures and with correlation to neuropsychological performance. More recently, a reduction in cortical thickness has also been observed [40]. Similar findings have been obtained with measurements of the lateral ventricles, corpus callosum, caudate nucleus, and hippocampus [41]. While cART can lead to improvements in brain volume, some neuronal injury and atrophy persists even after the introduction of these medications [42].

New imaging modalities have extended beyond structural MRI and show promise in HAND. Diffusion tensor imaging (DTI) measures the microstructural diffusion of water in the brain, a sensitive measure for injury within white matter tracts. Abnormalities in DTI are noted in HIV with clinical correlates, but are also noted in asymptomatic subjects [7, 43]. Magnetic resonance spectroscopy (MRS) measures regional changes in brain metabolites, with past studies demonstrating a reduction in $\mathrm{N}$-acetylaspartate (NAA), a marker of neuronal loss or damage, and increased myoinositol (MI), a marker of glial activation. Changes related to severity of cognitive impairment and a tendency toward normalization with cART have been described [44]. 18F-fluoro-deoxy-glucose positron emission tomography (18F-FDG-PET) can be used to measure metabolic activity. A recent study of 38 subjects with suppressed plasma HIV 
Fig. 1 Potential HIV-specific mechanisms of central nervous system (CNS) injury despite combination antiretroviral therapy (cART). HIV virus infects circulating monocytes, some of which may cross the bloodbrain barrier in an activated state. Immune activation may result from intra and extra CNS sources, including other peripheral reservoirs harboring HIV. CNS virus may not be adequately suppressed by cART due to decreased CPE. These mechanisms result in residual infection and inflammation, leading to astrocyte, macrophage, and microglial activation, neuronal dysfunction, and cognitive impairment

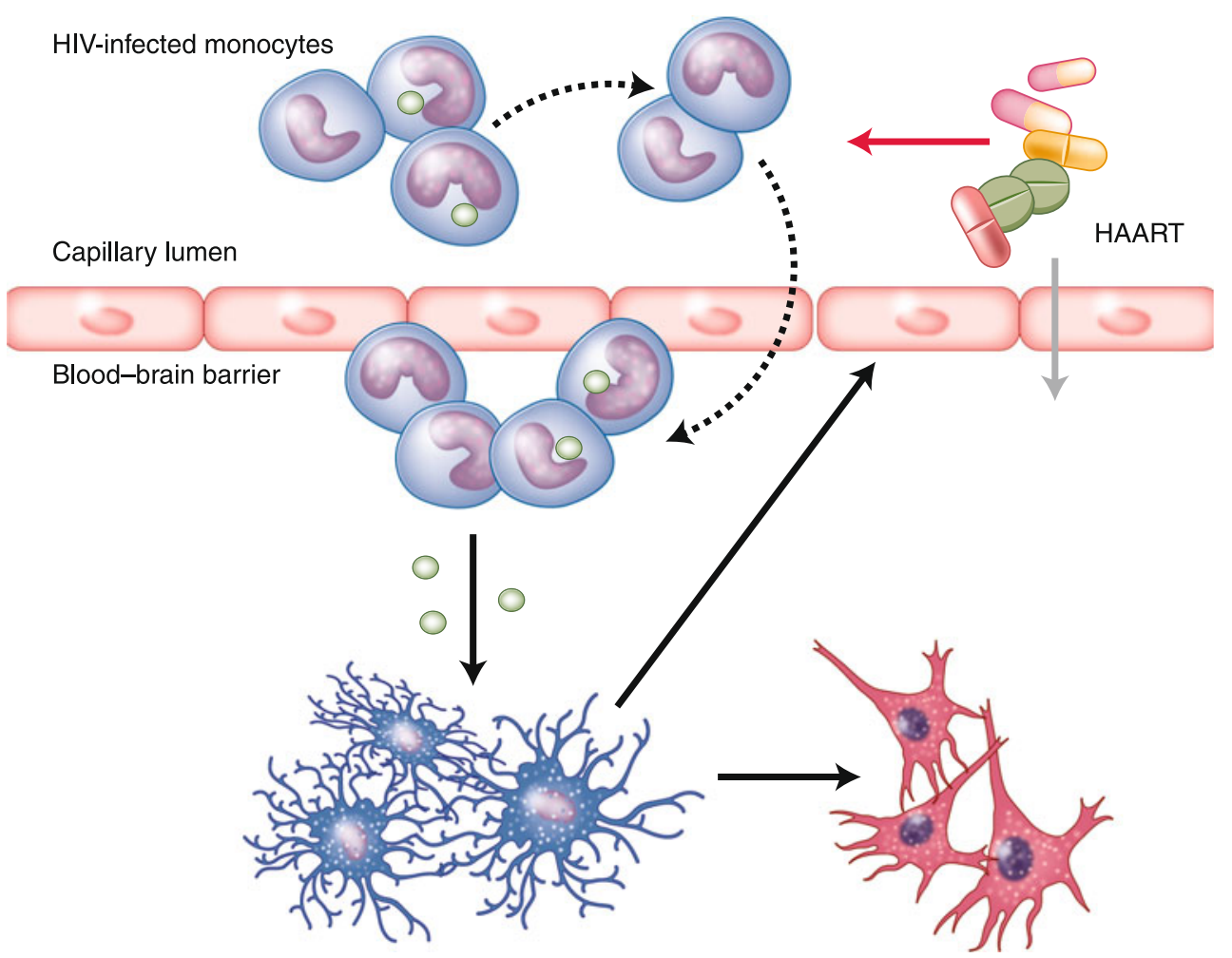

RNA for at least 3 years demonstrated abnormal mesialfrontal metabolic rate by $18 \mathrm{~F}-\mathrm{FDG}-\mathrm{PET}$ in over half of the cases, with correlation to shorter duration of HIV, fewer years on cART, and higher plasma levels of TNF $\alpha$ and IL-6 [45].

More recently, functional MRI (fMRI) techniques have been employed to measure blood-oxygen-level dependence (BOLD) as a marker of brain activation. In addition, arterial spin-labeled (ASL) can measure regional perfusion. In HIV, an inverse correlation has been described between baseline measurements of resting cerebral blood flow $(\mathrm{CBF})$ and degree of neurocognitive impairment with $\mathrm{CBF}$ reduced soon after serocoversion [46]. An effect of both aging and HIV has been described [47].

Together, these modalities demonstrate continued CNS abnormality despite cART and suggest that the most promising approaches may involve combination multimodal imaging. Unfortunately, many neuroimaging studies suffer from small heterogenous samples. Larger multicenter studies that include use of other biomarkers are needed. Given the resources required to apply it in the clinic, these neuroimaging biomarkers may have limited applicability in understanding the disease in the developing world where HIV is most prevalent.

\section{Other Contributing Factors to Cognitive Impairment in the Era of cART}

Early epidemiological data suggest a multifactorial etiology to cognitive impairment in the cART era. In addition to the direct and the indirect consequences of HIV and the immune response, contributions are most likely to result from medication effects (both prescription and nonprescription), coexisting morbid illnesses including cerebrovascular disease, and infections such as hepatitis C. There are limited data to further suggest differences in neuropathogenesis by HIV subtype.

The elevated frequency of dyslipidemia, smoking, and glucoregulatory disorders in HIV cohorts has raised concern for subclinical atherosclerotic disease with implications on cognition. The large multicenter D:A:D study and other groups have identified increased relative risk of combined cerebrovascular and cardiovascular morbidity in HIV subjects on cART [48]. HIV infection is associated with cellular activation in a manner that may promote atherosclerosis, and chronically infected cART-treated subjects demonstrate endothelial dysfunction when compared to controls $[49,50]$.

Few groups have demonstrated relationships between atherosclerotic risk and cognition. The Multicenter AIDS Cohort Study (MACS) identified a relationship between carotid endothelial thickness and cognition [51]. Elevated fasting glucose, insulin resistance and, separately, diabetes correlated to poorer overall cognitive performance in the Hawaii Aging with HIV Cohort (HAHC) study [52]. Using event-related electroencephalographic potentials, a synergistic relationship between HIV and elevated BMI was identified in a manner that suggests factors associated with obesity exacerbate HIV-related frontal brain dys- 
function [53]. In the multicenter SMART study (Strategies for Management of Antiretroviral Therapy) where $88 \%$ of the 292 subjects had undetectable plasma HIV RNA levels, prior cardiovascular disease, hypercholesterolemia, and hypertension were associated with poorer cognitive performance [54].

Hepatitis $\mathrm{C}$ virus $(\mathrm{HCV})$ is a frequent co-infection with HIV. The interaction between HCV and HIV on cognition has been controversial. Both viruses appear to invade CNS, causing neurocognitive problems, with some studies noting no exacerbation and others identifying interaction effects $[55,56]$. Noninfectious factors may also play a role. A study from South Africa demonstrated increased risk for HAND among individuals with post-traumatic stress disorder and alcohol abuse [57]. There is also speculation that antiretroviral medications themselves can contribute to cognitive clouding in a manner that could contribute to functional consequences. Among subjects with preserved immune function, neurocognitive measures improved, as a group, during treatment interruption in a small study of 167 subjects with good immune function [58], and neurological imaging with MRS [59] and fMRI [60] suggests that certain cART medications may have neurotoxic tendencies.

Although opportunistic infections continue to impact HIV care internationally, broad cART access provides opportunities to understand regional and subtype-specific neuropathogenesis. Early data suggested heightened cognitive risk associated with subtype B (most common in the United States and Europe) [61]; however, recent findings demonstrate a high prevalence in other settings where subtype $\mathrm{C}$ is common [62]. Data from Uganda revealed that cognitive impairment appeared to be more common among patients infected with subtype D than with subtype A [63]. These findings are supported by in vitro studies, providing a basis for the concept that differences by subtype could uncover therapeutic targets [61, 64-66].

\section{Conclusions: From Neuropathogenesis to Treatment}

Cognitive impairment in HIV disease remains common, despite effective cART. While symptoms are generally mild and severe dementia is rare, the impairment impacts quality of life and day-to-day functioning. Clinically relevant, validated diagnostic screening tools are few, highlighting an important unmet clinical need. Administering cART with good adherence remains the single most effective means of treating cognitive impairment in patients who are not on treatment; yet, treatment alone has been unsuccessful in eradicating HAND.

Important questions remain regarding optimal timing and composition of cART to optimize CNS treatment and preserve cognitive functioning. Studies evaluating adjuvant therapies have been described elsewhere and have been generally disappointing. A primary study of memantine did not demonstrate efficacy, but more recent analyses of MRS changes and results from the open-label phase of this study were more promising $[67,68]$. Reservoir-specific therapies targeting monocytes or CNS directly may have utility, and some new studies are underway. Nanoformulations of antiretroviral drugs (nanoART) are being developed with aims of improving drug delivery for CNS disorders [69]. Minimizing medication side effects, aggressive treatment of cerebrovascular risk factors, assessment and treatment of relevant co-infections and coexisting morbidities, physical exercise, and social engagement are likely to provide some benefit. While many of these recommendations are rooted in observational studies of HAND or published reports from other neurodegenerative diseases, they are not based on randomized intervention trials.

There remain large areas of research need. Cohort studies that focus on individuals with optimal peripheral control of virus would better inform residual impairment despite cART. Careful attention to the aging population that includes, whenever possible, neuropathological-clinical correlations, will be critical to understanding pathology as this population ages with chronic infection. Better clinical, imaging, and biomarker tools to identify and categorize impairment in the clinical setting are also required. Understanding the earliest changes to brain function after infection may inform mechanisms in a manner that could identify treatment targets.

Disclosure V. Valcour and Abbott: consulting for Merck, GlaxoSmithKline; P. Sithinamsuwan: none; S. Letendre: none; B. Ances: none.

Open Access This article is distributed under the terms of the Creative Commons Attribution Noncommercial License which permits any noncommercial use, distribution, and reproduction in any medium, provided the original author(s) and source are credited.

\section{References}

Papers of particular interest, published recently, have been highlighted as:

- Of importance

•• Of major importance

1. - Clifford DB. HIV-associated neurocognitive disease continues in the antiretroviral era. Top HIV Med. 2008;16(2):94-8. This article reports the preliminary findings of the CHARTER study in the US. This study evaluated over 1000 subjects and estimated the prevalence of HAND in the current era. It is striking that the proportion of subjects with some level of impairment has not changed since prior to $C A R T$, when considered by disease stage. 
2. Vivithanaporn P, Heo G, Gamble J, Krentz HB, Hoke A, Gill MJ, et al. Neurologic disease burden in treated HIV/AIDS predicts survival. A population-based study. Neurology. 2010.

3. Sacktor N, Nakasujja N, Robertson K, Clifford DB. HIV-associated cognitive impairment in sub-Saharan Africa - the potential effect of clade diversity. Nat Clin Pract Neurol. 2007;3(8):436-43.

4. Antinori A, Arendt G, Becker JT, Brew BJ, Byrd DA, Cherner M, et al. Updated research nosology for HIV-associated neurocognitive disorders. Neurology. 2007;69(18):1789-99.

5. McArthur JC. HIV dementia: an evolving disease. J Neuroimmunol. 2004;157(1-2):3-10.

6. Seeley WW, Crawford RK, Zhou J, Miller BL, Greicius MD. Neurodegenerative diseases target large-scale human brain networks. Neuron. 2009;62(1):42-52.

7. Hoare J, Fouche JP, Spottiswoode B, Joska JA, Schoeman R, Stein DJ, et al. White matter correlates of apathy in HIV-positive subjects: a diffusion tensor imaging study. J Neuropsychiatry Clin Neurosci. 2010;22(3):313-20.

8. Warriner EM, Rourke SB, Rourke BP, Rubenstein S, Millikin C, Buchanan $\mathrm{L}$, et al. Immune activation and neuropsychiatric symptoms in HIV infection. J Neuropsychiatry Clin Neurosci. 2010;22(3):321-8.

9. Valcour V, Watters MR, Williams AE, Sacktor N, McMurtray A, Shikuma C. Aging exacerbates extrapyramidal motor signs in the era of highly active antiretroviral therapy. J Neurovirol. 2008:1-6.

10. Morgan EE, Woods SP, Scott JC, Childers M, Beck JM, Ellis RJ, et al. Predictive validity of demographically adjusted normative standards for the HIV Dementia Scale. J Clin Exp Neuropsychol. 2008;30(1):83-90.

11. - Burdo TH, Soulas C, Orzechowski K, Button J, Krishnan A, Sugimoto $\mathrm{C}$, et al. Increased monocyte turnover from bone marrow correlates with severity of SIV encephalitis and CD163 levels in plasma. PLoS Pathog. 2010;6(4):e1000842. This study using the macaque model of SIV encephalitis demonstrates migration of monocytes from bone marrow to brain with correlations to degree of encephalitis.

12. Liu Y, Tang XP, McArthur JC, Scott J, Gartner S. Analysis of human immunodeficiency virus type 1 gp160 sequences from a patient with HIV dementia: evidence for monocyte trafficking into brain. J Neurovirol. 2000;6 Suppl 1:S70-81.

13. Valcour VG, Shiramizu BT, Shikuma CM. HIV DNA in circulating monocytes as a mechanism to dementia and other HIV complications. J Leukoc Biol. 2010;87(4):621-6.

14. Everall I, Vaida F, Khanlou N, Lazzaretto D, Achim C, Letendre $\mathrm{S}$, et al. Cliniconeuropathologic correlates of human immunodeficiency virus in the era of antiretroviral therapy. J Neurovirol. 2009:1-11.

15. Anthony IC, Ramage SN, Carnie FW, Simmonds P, Bell JE. Influence of HAART on HIV-related CNS disease and neuroinflammation. J Neuropathol Exp Neurol. 2005;64(6):529-36.

16. Kumar AM, Borodowsky I, Fernandez B, Gonzalez L, Kumar M. Human immunodeficiency virus type 1 RNA Levels in different regions of human brain: quantification using real-time reverse transcriptase-polymerase chain reaction. J Neurovirol. 2007;13 (3):210-24.

17. Churchill MJ, Wesselingh SL, Cowley D, Pardo CA, McArthur $\mathrm{JC}$, Brew BJ, et al. Extensive astrocyte infection is prominent in human immunodeficiency virus-associated dementia. Ann Neurol. 2009;66(2):253-8.

18. Muratori C, Mangino G, Affabris E, Federico M. Astrocytes contacting HIV-1-infected macrophages increase the release of CCL2 in response to the HIV-1-dependent enhancement of membrane-associated TNFalpha in macrophages. Glia. 2010.

19. •• Ellis R, Langford D, Masliah E. HIV and antiretroviral therapy in the brain: neuronal injury and repair. Nat Rev Neurosci. 2007;8 (1):33-44. This comprehensive review details cART era neuropa- thology in a manner that informs risk for neurodegeneration and provides a foundation for reversibility and treatment.

20. Anthony IC, Ramage SN, Carnie FW, Simmonds P, Bell JE. Accelerated Tau deposition in the brains of individuals infected with human immunodeficiency virus- 1 before and after the advent of highly active anti-retroviral therapy. Acta Neuropathol. 2006;111(6):529-38.

21. Khanlou N, Moore DJ, Chana G, Cherner M, Lazzaretto D, Dawes $\mathrm{S}$, et al. Increased frequency of alpha-synuclein in the substantia nigra in human immunodeficiency virus infection. $\mathrm{J}$ Neurovirol. 2009;15(2):131-8.

22. Achim CL, Adame A, Dumaop W, Everall IP, Masliah E. Increased Accumulation of Intraneuronal Amyloid beta in HIVInfected Patients. J Neuroimmune Pharmacol. 2009.

23. Clifford DB, Fagan AM, Holtzman DM, Morris JC, Teshome M, Shah AR, et al. CSF biomarkers of Alzheimer disease in HIVassociated neurologic disease. Neurology. 2009;73(23):1982-7.

24. Ances BM, Christensen JJ, Teshome M, Taylor J, Xiong C, Aldea $\mathrm{P}$, et al. Cognitively unimpaired HIV-positive subjects do not have increased 11C-PiB: A case-control study. Neurology. 2010;75 (2):111-5.

25. Gisslen M, Hagberg L, Brew BJ, Cinque P, Price RW, Rosengren L. Elevated cerebrospinal fluid neurofilament light protein concentrations predict the development of AIDS dementia complex. J Infect Dis. 2007;195(12):1774-8.

26. Letendre S, Marquie-Beck J, Capparelli E, Best B, Clifford D, Collier AC, et al. Validation of the CNS Penetration-Effectiveness rank for quantifying antiretroviral penetration into the central nervous system. Arch Neurol. 2008;65(1):65-70.

27. Annamalai L, Bhaskar V, Pauley DR, Knight H, Williams K, Lentz M, et al. Impact of Short-Term Combined Antiretroviral Therapy on Brain Virus Burden in Simian Immunodeficiency Virus-Infected and CD8+ Lymphocyte-Depleted Rhesus Macaques. Am J Pathol. 2010.

28. Canestri A, Lescure FX, Jaureguiberry S, Moulignier A, Amiel C, Marcelin AG, et al. Discordance between cerebral spinal fluid and plasma HIV replication in patients with neurological symptoms who are receiving suppressive antiretroviral therapy. Clin Infect Dis. 2010;50(5):773-8.

29. Eden A, Price R, Hagberg L, Gisslen M. CSF Escape in uncommon in HIV-1-infected patients on stable ART. 17th Conference on Retroviruses and Opportunistic Infections, 2010. San Francisco, CA.

30. Schnell G, Spudich S, Harrington P, Price RW, Swanstrom R. Compartmentalized human immunodeficiency virus type 1 originates from long-lived cells in some subjects with HIV-1associated dementia. PLoS Pathog. 2009;5(4):e1000395.

31. Letendre SL, McCutchan JA, Childers ME, Woods SP, Lazzaretto D, Heaton RK, et al. Enhancing antiretroviral therapy for human immunodeficiency virus cognitive disorders. Ann Neurol. 2004;56 (3):416-23.

32. Marra CM, Zhao Y, Clifford DB, Letendre S, Evans S, Henry K, et al. Impact of combination antiretroviral therapy on cerebrospinal fluid HIV RNA and neurocognitive performance. Aids. 2009;23(11):1359-66.

33. Patel K, Ming X, Williams PL, Robertson KR, Oleske JM, Seage $\mathrm{GR}$, 3rd. Impact of HAART and CNS-penetrating antiretroviral regimens on HIV encephalopathy among perinatally infected children and adolescents. Aids. 2009.

34. Letendre S, McClemon D, Ellis R, Munoz-Moreno J, Way L, Franklin D, et al. Persistent HIV in the central nervous system during treatment is associated with worse ART penetration and cognitive impairment. 16th Conference on Retroviruses and Opportunistic Infections, 2009. Montreal, CA.

35. McArthur JC, Brew BJ, Nath A. Neurological complications of HIV infection. Lancet Neurol. 2005;4(9):543-55. 
36. Alexaki A, Wigdahl B. HIV-1 infection of bone marrow hematopoietic progenitor cells and their role in trafficking and viral dissemination. PLoS Pathog. 2008;4(12):e1000215.

37. Shiramizu B, Paul R, Williams A, Shikuma C, Watters M, Grove J, et al. HIV proviral DNA associated with decreased neuropsychological function. J Neuropsychiatry Clin Neurosci. 2007;19(2):157-63.

38. Valcour VG, Shiramizu BT, Shikuma CM. HIV DNA in circulating monocytes as a mechanism to dementia and other HIV complications. J Leukoc Biol. 2010.

39. Hocquloux L, Avettand-Fenoel V, Jacquot S, Prazuck T, melard A, Viard J, et al. Abstract \#515: Better HIV DNA depletion and CD4 restoration with HAART initiated at the time of primary HIV infection than with HAART started during chronic HIV infection. 16th Conference of Retroviruses and Opportunistic Infections, February 2009. Montreal, CA.'.

40. Thompson PM, Dutton RA, Hayashi KM, Toga AW, Lopez OL, Aizenstein HJ, et al. Thinning of the cerebral cortex visualized in HIV/AIDS reflects CD4+ T lymphocyte decline. Proc Natl Acad Sci U S A. 2005;102(43):15647-52.

41. Wang Y, Zhang J, Gutman B, Chan TF, Becker JT, Aizenstein HJ, et al. Multivariate tensor-based morphometry on surfaces: application to mapping ventricular abnormalities in HIV/AIDS. Neuroimage. 2010;49(3):2141-57.

42. Dewey J, Hana G, Russell T, Price J, McCaffrey D, Harezlak J, et al. Reliability and validity of MRI-based automated volumetry software relative to auto-assisted manual measurement of subcortical structures in HIV-infected patients from a multisite study. Neuroimage. 2010;51(4):1334-44.

43. Gongvatana A, Schweinsburg BC, Taylor MJ, Theilmann RJ, Letendre SL, Alhassoon OM, et al. White matter tract injury and cognitive impairment in human immunodeficiency virus-infected individuals. J Neurovirol. 2009;15(2):187-95.

44. Stankoff B, Tourbah A, Suarez S, Turell E, Stievenart JL, Payan $\mathrm{C}$, et al. Clinical and spectroscopic improvement in HIVassociated cognitive impairment. Neurology. 2001;56(1):112-5.

45. Andersen AB, Law I, Krabbe KS, Bruunsgaard H, Ostrowski SR, Ullum $\mathrm{H}$, et al. Cerebral FDG-PET scanning abnormalities in optimally treated HIV patients. J Neuroinflammation. 2010;7:13.

46. Ances BM, Sisti D, Vaida F, Liang CL, Leontiev O, Perthen JE, et al. Resting cerebral blood flow: a potential biomarker of the effects of HIV in the brain. Neurology. 2009;73(9):702-8.

47. Ances BM, Vaida F, Yeh MJ, Liang CL, Buxton RB, Letendre S, et al. HIV infection and aging independently affect brain function as measured by functional magnetic resonance imaging. J Infect Dis. 2010;201(3):336-40.

48. d'Arminio A, Sabin CA, Phillips AN, Reiss P, Weber R, Kirk O, et al. Cardio- and cerebrovascular events in HIV-infected persons. Aids. 2004;18(13):1811-7.

49. Blanco JJ, Garcia IS, Cerezo JG, de Rivera JM, Anaya PM, Raya PG, et al. Endothelial function in HIV-infected patients with low or mild cardiovascular risk. J Antimicrob Chemother. 2006;58(1):133-9.

50. Appay V, Sauce D. Immune activation and inflammation in HIV-1 infection: causes and consequences. J Pathol. 2008;214(2):231-41.

51. Becker JT, Kingsley L, Mullen J, Cohen B, Martin E, Miller EN, et al. Vascular risk factors, HIV serostatus, and cognitive dysfunction in gay and bisexual men. Neurology. 2009;73(16):1292-9.

52. Valcour V, Sacktor NC, Paul RH, Watters MR, Selnes OA, Shiramizu BT, et al. Insulin Resistance Is Associated With Cognition Among HIV-1-Infected Patients: The Hawaii Aging With HIV Cohort. J Acquir Immune Defic Syndr. 2006;43(4):405-10.

53. Bauer LO. Interactive effects of HIV/AIDS, body mass, and substance abuse on the frontal brain: A P300 study. Psychiatry Res. 2010
54. Wright EJ, Grund B, Robertson K, Brew BJ, Roediger M, Bain MP, et al. Cardiovascular risk factors associated with lower baseline cognitive performance in HIV-positive persons. Neurology. 2010.

55. Letendre S, Paulino AD, Rockenstein E, Adame A, Crews L, Cherner M, et al. Pathogenesis of hepatitis $\mathrm{C}$ virus coinfection in the brains of patients infected with HIV. J Infect Dis. 2007;196 (3):361-70.

56. Clifford DB, Smurzynski M, Park LS, Yeh TM, Zhao Y, Blair L, et al. Effects of active HCV replication on neurologic status in HIV RNA virally suppressed patients. Neurology. 2009;73 (4):309-14

57. Joska JA, Fincham DS, Stein DJ, Paul RH, Seedat S. Clinical correlates of HIV-associated neurocognitive disorders in South Africa. AIDS Behav. 2010;14(2):371-8.

58. Robertson KR, Su Z, Margolis DM, Krambrink A, Havlir DV, Evans $S$, et al. Neurocognitive effects of treatment interruption in stable HIV-positive patients in an observational cohort. Neurology. 2010;74(16):1260-6.

59. Schweinsburg BC, Taylor MJ, Alhassoon OM, Gonzalez R, Brown GG, Ellis RJ, et al. Brain mitochondrial injury in human immunodeficiency virus-seropositive $(\mathrm{HIV}+)$ individuals taking nucleoside reverse transcriptase inhibitors. J Neurovirol. 2005;11 (4):356-64.

60. Ances BM, Roc AC, Korczykowski M, Wolf RL, Kolson DL. Combination antiretroviral therapy modulates the blood oxygen level-dependent amplitude in human immunodeficiency virusseropositive patients. J Neurovirol. 2008;14(5):418-24.

61. Rao VR, Sas AR, Eugenin EA, Siddappa NB, Bimonte-Nelson H, Berman JW, et al. HIV-1 clade-specific differences in the induction of neuropathogenesis. J Neurosci. 2008;28(40):10010 6.

62. Gupta JD, Satishchandra P, Gopukumar K, Wilkie F, WaldropValverde D, Ellis R, et al. Neuropsychological deficits in human immunodeficiency virus type 1 clade $\mathrm{C}$-seropositive adults from South India. J Neurovirol. 2007;13(3):195-202.

63. Sacktor N, Nakasujja N, Skolasky RL, Rezapour M, Robertson K, Musisi S, et al. HIV subtype D is associated with dementia, compared with subtype A, in immunosuppressed individuals at risk of cognitive impairment in Kampala, Uganda. Clin Infect Dis. 2009;49(5):780-6.

64. Mishra M, Vetrivel S, Siddappa NB, Ranga U, Seth P. Clade-specific differences in neurotoxicity of human immunodeficiency virus-1 B and C Tat of human neurons: significance of dicysteine C30C31 motif. Ann Neurol. 2008;63(3):366-76.

65. Gandhi N, Saiyed Z, Thangavel S, Rodriguez J, Rao KV, Nair MP. Differential effects of HIV type 1 clade B and clade C Tat protein on expression of proinflammatory and antiinflammatory cytokines by primary monocytes. AIDS Res Hum Retroviruses. 2009;25 (7):691-9.

66. Samikkannu T, Saiyed ZM, Rao KV, Babu DK, Rodriguez JW, Papuashvili MN, et al. Differential regulation of indoleamine-2,3dioxygenase (IDO) by HIV type 1 clade $\mathrm{B}$ and C Tat protein. AIDS Res Hum Retroviruses. 2009;25(3):329-35.

67. Zhao Y, Navia BA, Marra CM, Singer EJ, Chang L, Berger J, et al. Memantine for AIDS dementia complex: open-label report of ACTG 301. HIV Clin Trials. 2010;11(1):59-67.

68. Schifitto G, Navia BA, Yiannoutsos CT, Marra CM, Chang L, Ernst T, et al. Memantine and HIV-associated cognitive impairment: a neuropsychological and proton magnetic resonance spectroscopy study. Aids. 2007;21(14):1877-86.

69. Nowacek A, Gendelman HE. NanoART, neuroAIDS and CNS drug delivery. Nanomedicine (Lond). 2009;4(5):557-74. 